\title{
Embedding Sustainable Facilities Management in the Management of Public Buildings in Nigeria
}

\author{
Adeni Abigo ${ }^{1}$, Della Madgwick ${ }^{2}$, Kassim Gidado ${ }^{3}$ and Stephen Okonji ${ }^{4}$
}

\begin{abstract}
The built environment accounts for a significant detrimental impact on the natural environment as a result of its substantial use of energy and carbon emissions. Based on their energy usage and carbon emission, the operational phase of buildings has the most injurious effect on the environment. This paper focuses on the property management aspect of facilities management (FM) and presents an analysis of property management in the UK and Nigeria with reference to sustainability. It addresses the need of integrating sustainable practices in the management of public buildings in Nigeria. The research methodology for this paper is based on information and data collated from literature and two structured questionnaires targeted at professionals and maintenance personnel in charge of the maintenance of public buildings in the UK and Nigeria. The primary findings of this paper reveal that as a result of no/poor maintenance strategies for maintaining public buildings, the average condition of public buildings in Nigeria is fair (on a scale 1 - poor to 5 excellent). Also, the absence of regulations/legislations, sustainable policies, awareness, training of maintenance personnel, knowledge and senior management commitment are the most severe barriers to the implementation of sustainable facilities management (SFM) in the management of public buildings in Nigeria. Based on the findings, this paper recommends a framework for the implementation of sustainable practices in the management of public buildings in Nigeria.
\end{abstract}

Keywords: facilities management, property management, sustainability, sustainable facilities management.

\section{Introduction}

There is a drastic change in global climate which is having an adverse effect on the wellbeing of the global population. Recent extreme weather events such as the hurricane Katrina which hit New Orleans, United States of America in 2005, flooding in most parts of the world and earthquake/tsunami and hurricane Irene in Japan and United States of America, points out the need to address the threat of global climate change. According to the conclusions of the Stern review, now is the time to take strong actions in order to avoid the worst impacts of climate change.

Apart from the fact that climate change has been described as the biggest global threat of the $21^{\text {st }}$ century (Williams and Sutrisna, 2010), the hardest hit of climate change is anticipated to be developing countries as poverty reduction efforts around the globe are

Research Student, School of Environment and Technology, University of Brighton, Lewes Road, BN2 4GJ, Brighton, E-mail: A.Adeni1@ uni.brighton.ac.uk.

2 Senior Lecturer, School of Environment and Technology, University of Brighton, Lewes Road, BN2 4GJ, Brighton, Tel: +44 (0) 1273-642373, E-mail: D.Madgwick@brighton.ac.uk.

3 Principal Lecturer, School of Environment and Technology, University of Brighton, Lewes Road, BN2 4GJ, Brighton, Tel: +44 (0) 1273-642394, E-mail: K.I.Gidado@ brighton.ac.uk.

4 Research Student, School of Applied Science, Cranfield University, MK43 0AL, Bedford, E-mail: Stephen.okonji@cranfield.ac.uk. 
allegedly faced with a major drawback (World Bank, 2011). There is therefore an urgent need for Nigeria as a developing country to take early and rapid steps towards achieving sustainable development.

In its simplest form and as first defined by the report of the Brundtland Commission in 1987, sustainable development is a "development that meets the needs of the present without compromising the ability of future generations to meet their own needs".

In the quest to meet sustainable development, the Kyoto Protocol was adopted in Kyoto, Japan in 1997 and came into force in 2005. The Kyoto Protocol is an international agreement setting targets for industrialised countries to cut their greenhouse gas emissions. The need for urgent steps towards attaining sustainability was recognised and the acceptance that efforts should be made to tackle the causes of climate change led to the signing up to the Kyoto Protocol by member states of the European Union and other signatories. In order to attain sustainability and achieve $8 \%$ carbon reduction target, EU countries have come up with carbon reduction targets (Uk 12.5\%, Germany 21\%, Denmark $21 \%$ etc) to be met between 2008 and 2012 (Grant et al., 2009). However, one of the limitations of the Kyoto Protocol is its exclusion of developing countries from the pursuit of sustainable development. In the opinion of the authors of this paper, the world is a global village and the major changes in the global climate affect all life on earth. Thus, every country has a stake in the pursuit of sustainable development as every contribution towards sustainability will be appreciated.

With an estimated $20 \%$ water usage, $25-40 \%$ energy usage, $30-40 \%$ solid waste generation and 30-40\% global greenhouse gas emission (UNEP, 2007), the built environment accounts for a significant detrimental impact on the natural environment currently contributing to the changes in the global climate. Also, CIOB (2004) estimated that only $5 \%$ generated energy is used in construction process of buildings while $45 \%$ is used to power and maintain the buildings. This indicates that the operational phases of buildings have the most injurious effect on the environment.

It can be deduced from the foregoing that if $45 \%$ of generated energy is used in the operational phase of buildings, the facilities manager whose key responsibility is at this phase of buildings is at the forefront of mitigating climate changes by delivering sustainable asset management in the built environment (Elmualim et al., 2009).

Nigeria has an estimated population of one hundred and fifty million, two hundred and fifteen thousand, five hundred and seventy three people and is considered to be Africa's most populous country (Index Mundi, 2011). Like most developing countries, public enterprises were established in Nigeria in order to provide social services and to propel the vehicle of socio-economic development (Olowu and Sako, 2002). Nwanze (2010) estimated the total number of public enterprises in Nigeria as at 2009 to be one thousand five hundred (600 at Federal level and 900 at State and Local Government level). However, Nigeria like many developing countries has recorded poor performance in the operation of public enterprises (Nwoye, 2002). The economic recession in the early 1980's brought about a focus on public enterprises in Nigeria. This revealed that the sector was crowded by problems such as misuse of monopoly powers, bureaucratic red tape, heavy dependence on Government treasury, mismanagement and corruption (Alabi, et al., 2010). The issue of mismanagement is also evident in the condition of public buildings in Nigeria. In spite of the huge amount of money spent on erecting public buildings in Nigeria, most of them are in shabby state of both structural and decorative disrepair as a result of poor 
maintenance (Iyagba, 2005). The government seems to be interested in setting up new buildings while leaving the old buildings to rot and decay. For instance, the buildings in most Federal Government owned Universities is in a state of structural disrepair but the Government is presently undergoing the construction of six (6) new Federal Universities across the country. It is perceived that at its present state, public buildings use a high level of energy, water and its waste generation is extremely high due to lack of maintenance. Lewis et al., (2011) posited that systems which are not maintained consume more energy due to equipment wear. This suggests that public buildings in Nigeria as a result of their non-maintenance are detrimental to the natural environment.

There is therefore a need to proffer systems of incorporating sustainable practices in the management of public buildings in Nigeria. This is required to improve the condition of public buildings (buildings that consume less resource) and attain sustainability.

\section{Sustainable Facilities Management}

There is a lack of research on sustainable facilities management with reference to the maintenance and operation of buildings. However, sustainable facilities management (SFM) was described by Nielsen et al., (2009), as an "umbrella" for various ways of minimising flows of energy, water and waste in the daily operation of buildings. In essence, reducing energy and water usage in the operation of buildings and waste generated from the daily operations and management of buildings will invariably lead to reduced operational cost of buildings. This is evident in the $13.8 \%$ reduction of carbon emissions and $£ 13 \mathrm{M}$ (Thirteen Million Pounds) savings in energy bills within 12 months (May 2010 and May 2011) achieved by the UK Government across 3,000 public buildings (CIBSE, 2011). This indicates that, apart from preserving the environment, incorporating sustainable practices in the management of buildings comes with the benefit of reduced operational cost.

In the bid to meet the requirements of the Kyoto Protocol, most European Union countries with the directive of the European Union Commission, came up with legislations and set targets in cutting down their greenhouse gas emissions especially in the built environment. For example, in the UK, a mandatory Energy Performance Certificate (EPC) was introduced in 2007 to be provided by home owners for the sale/rent of their homes. Information on the energy performance of the home is displayed on the EPC to prospective buyers/renters, also commercial buildings that are sold or let are expected to display an EPC. The EPC provides information on the buildings energy efficiency on a scale of A (very efficient) to $\mathrm{G}$ (least efficient). In 2008 also, the UK Government introduced the Display Energy Certificates (DECs) for UK public buildings measuring over $1,000 \mathrm{~m}^{2}$. The introduction of these and other legislations/regulations points out the importance of the sustainability agenda to the property sector in the UK.

In the built environment profession, sustainability is increasingly becoming an important issue. The facilities manager is expected to apply the regulations to reduce carbon emission in the management of facilities. A majority of the burden for the reduction of carbon emissions in the built environment lies with the facilities managers as their key responsibility is at the operational phase of buildings which lasts much longer than the construction phase. Thus, Elmualim et al. (2009) stated that the facilities manager is at the forefront of delivering sustainable facilities management and contributing to sustainable development. 
There are various systems of sustainable practices which are employed in the management and operation of buildings in order to reduce their carbon emissions and energy usage. Some of such systems includes: Building Information Modelling (BIM), Audits - energy, water and waste audits, sustainable cleaning products, adequate metering and monitoring, etc.

Research was carried out by Nielsen et al., (2009) in order to evaluate the extent to which SFM is integrated in the operations of housing estates in Denmark. The research identified social housing, owner - occupier/private co-operatives and private renting as the three types of ownership in the housing sector. The research further identified individual metering, energy labelling of buildings, Green accounting for residential buildings, Green homes and Energy management as some of the regulations and tools for sustainable building operations. The results from the research showed good practices of SFM in the social housing sector that led to reduction in energy, water and waste generation. The research concluded that different types of ownership will demand different types of FM solutions thus determining the success of SFM. Although the outcome of the research is limited to residential housing sector, sustainable practices can be applied to all housing types. However, the success of a particular sustainable strategy in an organisation does not guarantee its success in another organisation especially if their activities differ.

The findings from the research carried out by Elmualim et al. (2009) to establish the level of commitment and knowledge chasm in practicing SFM indicated that sustainability is an important issue to organisations. Respondents to the research questionnaire stated that reports on energy efficiency, recycling and waste reduction were key in the sustainability report of their organisations. The research further states that a lack of consensual understanding and focus of individuals and organisations about sustainability is a barrier for implementing SFM.

A further research by Elmualim et al. (2010) revealed that time constraints, lack of knowledge and senior management commitment are the main barriers to the implementation of consistent SFM policies and practice. However, the research did not suggest ways of overcoming the overwhelming challenges of achieving SFM.

It is evident that the practice of SFM has been welcomed by many organisations but there exist in these same organisations barriers impeding the success of integrating SFM in the daily operations of buildings. In order to achieve sustainable development in FM, sustainability should be embedded at both the strategic, tactical and operational phase of a facility. The facilities manager should not be left with the difficulties of managing just the facility upon completion when their contributions and input at the design stage can help shape better facilities. Shah (2007), has argued that the influence of the facilities manager at the design stage (strategic level), will aid in achieving the targets and the pursuit of sustainability in the built environment and that the FM industry has a major role to play by influencing colleagues and the management hierarchy within the client's organisation to understand the benefits and impacts of sustainable development.

\section{Management of Public Buildings in United Kingdom}

A research by Olakunle (2010) on the management of hard services within UK's public buildings revealed that the maintenance strategy adopted for the management of buildings was from the outcome of an annual performance appraisal undertaken with the maintenance department. Also, performance standards were written into FM contracts with minimum performance level threshold and also allowing sanctions against non-achievers. The review process is characterised by; 
- Review and planning process: Past performances are appraised and the factors that caused a low performance are critically reviewed in order to improve on future performance

- Objective - based performance is appraised against previous year's objectives in order to come up with new set of objectives for the next year

- Creation of development opportunity: Plans are developed in order to give extra skills and knowledge needed to achieve the new objectives and to prepare for additional responsibilities

- Participative: Past performances were acknowledged to be by the operatives but the operatives still depend on the managers for their input

- Empowering: Problems are analysed and decisions on the formulation of objectives and how the objectives can be achieved are reached

The researcher concluded by stating that implementation of performance appraisal aided in the reduction of corrective maintenance.

The maintenance system adopted could be seen as a planned maintenance system and according to Ravetz (2008), such system adopted by the public sector has aided in making public sector homes significantly more energy efficient than private homes.

\section{Management of Public Buildings in Nigeria}

One of the greatest economic and social problem of Nigeria as a nation is the general absence of a maintenance culture (Iyagba, 2005). The issue of poor maintenance culture and "I don't care" attitude, like a disease has eaten deep into the marrow of Nigeria and is manifested in the way public buildings are managed. Buildings are set up and expected to live their life span without a bit of management. Anele (2010) perceives that Nigeria will continue to waste scarce financial resources on building new infrastructure which cannot be sustained if urgent steps are not taken to embrace maintenance culture.

A research by Adenuga et al., (2010) on the need for effective maintenance practices in public buildings, investigated the causes of neglect of maintenance responsibilities and concluded that the lack of maintenance culture in the country, lack of maintenance knowledge, lack of emphasis on training, retraining and continuing education on effective management by the establishment, indiscipline and ignorance on the part of users, absence of planned maintenance programme and reactive maintenance, complexity of design, noninvolvement of maintenance team at design stage and inadequate funds for maintenance are the factors affecting maintenance management of public building in Nigeria

The authors of this paper agree with the findings of the research on the causes of neglect of maintenance responsibilities especially in the area of lack of maintenance knowledge. In Nigeria, the management of land, buildings and facilities, plant and machinery is perceived as the responsibility of the Estate Surveyor and Valuer. Given the skills and training, the Estate Surveyor and Valuer do not have the competence to appropriately manage facilities as they have limited knowledge in this field (Adewunmi and Ogunba, 2008). However, the authors of this paper, fairly disagree with the issue of lack of adequate provision of funds as reasons for the condition of public buildings in Nigeria but will rather state that corruption by highly placed individuals in the public sector is responsible for this problem. On a scale from 10 (highly clean) to 0 (highly corrupt) on the perceived levels of public sector corruption in 174 countries in the world by Transparency International in 2010, 
Nigeria was ranked 2.4. This clearly shows the high level of corruption exhibited in the public sector and by public officers. Corruption especially in the public sector has brought about instability and failure of most of the public institutions.

\section{Research Methodology}

The study was carried out by a detailed literature review, a pilot study and questionnaire survey. Two structured questionnaires comprising of eighteen questions targeted at those in charge of the maintenance of public buildings in Nigeria and the UK were administered. The essence of sending questionnaires to practicing professionals in the UK is to appraise the management of public buildings in the UK and attain lessons and better practices (if any) that can be embedded in the management of public buildings in Nigeria. An on-line based questionnaire was created for UK respondents and was posted on group discussion pages of BIFM website and the Linked in (a social networking website) home pages of sustainability special interest group, Rising FM's, FM professionals and RICS while hand delivery questionnaires were administered to Nigeria respondents.

A total of one hundred and three questionnaires out of one hundred and seventy administered to the Nigeria participants were found useful for analysis while out of twenty eight participants in the UK, only twenty responses were considered to be of quality and useful for analysis.

Data collated were analysed using the frequency distribution and severity index. The mathematical expression of severity index as adopted from Akere and Gidado (2003) and Kadir et al (2005) is;

$$
\text { Severity Index }(S I)=\frac{\sum R_{w} w}{R_{t}}
$$

Where $R_{w}$ is the number of respondents, $w$, the weight or points assigned and $R_{t}$, the total no of responses obtained from that variable. In interpreting the degree of severity, the scale on the rating of the issues is;

S.I $\leq 1.4$ implies not serious, not difficult or never felt its effect

S.I $=1.5-2.4$ implies moderately serious or difficult or felt its effect some of the time S.I $=2.5-3.4$ implies usually serious, usually difficult or felt its effect many times S.I $\geq 3.5$ implies very serious, very difficult or felt its effect most of the time.

\section{Results and Discussions}

The data collated from the questionnaire identified $65 \%$ of the UK respondents as Facilities Managers, $30 \%$ as Building Service Managers/Engineers and $5 \%$ as Director/Head of Estate and Contracts while $48 \%$ of the Nigeria respondents were identified as Estate Surveyors, 21\% as Engineers, 14\% as Technical staff, 7\% as Quantity Surveyors, $5 \%$ as Facilities Managers and 1\% each as Vice Principal special duties, Maintenance Officer, Director of Works, Cost Control Officer and Town Planner.

Data collated from the questionnaire are analysed and the findings are discussed below: 

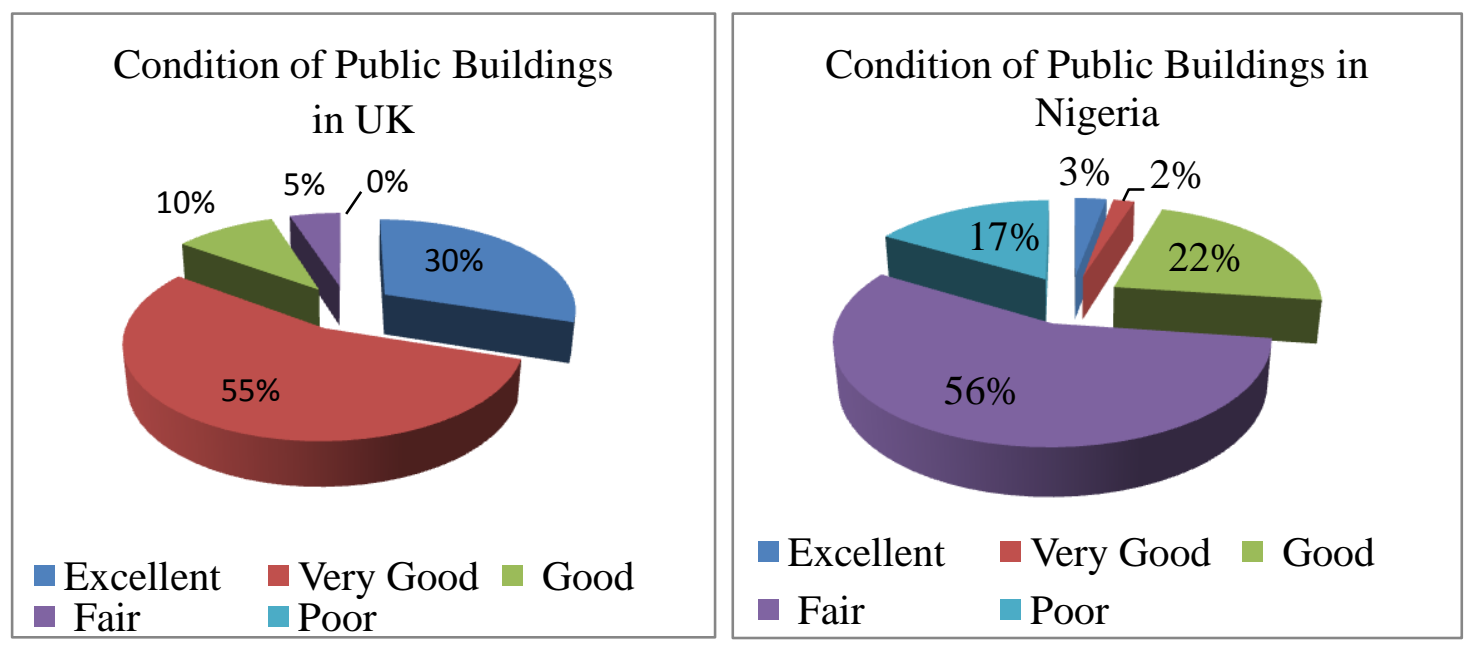

Figure 1. Analysis from UK and Nigeria Participants on the Condition of their Organisation's Building(s)

The results shown in figure 1 suggest the presence of good maintenance practice in the management of public buildings in the UK and further demonstrate high emphasis on maintenance culture which has engineered the good property management practice. These good practices are perceived to be responsible for the condition of public buildings in the UK. The results also illustrates to a great extent the poor emphasis placed on maintenance in Nigeria. In the opinion of the authors of this paper, the buildings in excellent and very good conditions from the Nigeria analysis are those with an average age less than ten. Thus, the conditions of UK public buildings are perceived to be better than that of Nigeria. The results of figure 1 can also be linked to the responses from the participants when asked if their organisation had a maintenance strategy. The UK participants all replied that theirs had a maintenance strategy while $88 \%$ of Nigeria participants stated their organisation had no maintenance strategy and $12 \%$ stated theirs' had. From the analysis, it can be established that the presence of a maintenance strategy is responsible for the condition of public buildings in the UK. It is evident that for buildings to remain in good condition, it is critical to implement good practices of predictive, preventive and corrective maintenance.

Table 1. Analysis from UK Participants on the Barriers to the Implementation of Consistent SFM Practices in their Organisation

\begin{tabular}{|c|c|c|c|}
\hline $\mathrm{S} / \mathrm{N}$ & $\begin{array}{l}\text { Barriers to the Implementation of Consistent Sustainable } \\
\text { Practice }\end{array}$ & $\begin{array}{l}\text { Severity } \\
\text { Index }\end{array}$ & Rank \\
\hline 1 & Time constraints & 3.4 & 1 \\
\hline 2 & Financial constraints & 3.0 & 2 \\
\hline 3 & Lack of training of maintenance personnel & 2.7 & 3 \\
\hline 4 & Lack of sustainable policies & 2.3 & 4 \\
\hline 5 & Lack of senior management commitment & 2.2 & 5 \\
\hline 6 & Lack of awareness & 2.1 & 6 \\
\hline 7 & Lack of knowledge by maintenance personnel & 2.1 & 6 \\
\hline 8 & Lack of regulations/legislations & 1.6 & 7 \\
\hline 9 & Lack of the enforcement of regulations/legislations & 1.6 & 7 \\
\hline
\end{tabular}


Table 1 and 2 show the tabular summary of the results from analysis showing the severity indexes of the barriers to the implementation of sustainable practices in the management of public buildings in the UK and Nigeria:

The result on table 1 demonstrates that time constraints, financial constraints and lack of training of maintenance personnel are the most severe barriers affecting the implementation of consistent SFM practices. Based on the results of table 1 and the findings of Elmualim et al. (2010), time constraints seem to be an intense barrier encountered by all maintenance personnel in their various organisations. This could be as a result of the commitment required in other to achieve sustainability (maintenance strategy, monitoring, targeting, reporting etc). Also, with reference to the severity scale, results from table 1 illustrates that the effect of the other barriers are minimal.

Table 2. Analysis from Nigeria Participants on the Barriers to the Implementation of SFM Practices in their Organisation

\begin{tabular}{llll}
\hline & & Severity & \\
S/N & Barriers to the Implementation of Sustainable Practice & Index & Rank \\
\hline 1 & Lack of regulations/legislations & 5.0 & 1 \\
2 & Lack of sustainable policies & 4.8 & 2 \\
3 & Lack of awareness & 4.7 & 3 \\
4 & Lack of senior management commitment & 4.5 & 4 \\
5 & Lack of knowledge by maintenance personnel & 4.2 & 5 \\
6 & Lack of training of maintenance personnel & 4.1 & 6 \\
7 & Financial constraints & 3.3 & 7 \\
8 & Time constraints & 3.2 & 8 \\
9 & & Not & \\
\hline
\end{tabular}

The results on table 2 show a huge gap in the findings between the UK and Nigeria analysis. This can be associated to the fact that UK has a legal obligation to reduce carbon emissions and this engineered the introduction of regulations/legislations and targets by the UK Government which has aided in minimising the severe effect of other barriers in the implementation of SFM while Nigeria as a developing country has no express obligation to reduce carbon emissions. However, taking into consideration that the world is a global village and the impact of climate change will have more effect on developing countries, Nigeria must work towards reducing its carbon emissions. If the actions of UK are imbibed into the Nigeria system then Nigeria will be making progress in the right direction towards achieving sustainability in the management of public buildings.

\section{Embedding Sustainable Practices in the Management of Public Buildings in Nigeria}

The findings from the primary data and the review of literatures for this study indicates that in order to embed sustainable practices in the management of public buildings in Nigeria, all tiers of Government in Nigeria, professionals in charge of the management of 
public buildings and the populace need to take crucial steps and actions. Thus, the authors of this paper have developed a framework that will enable the implementation of SFM in the management of public buildings in Nigeria. The proposed framework comprises of six interconnected phases and is illustrated on figure 2 of this paper.

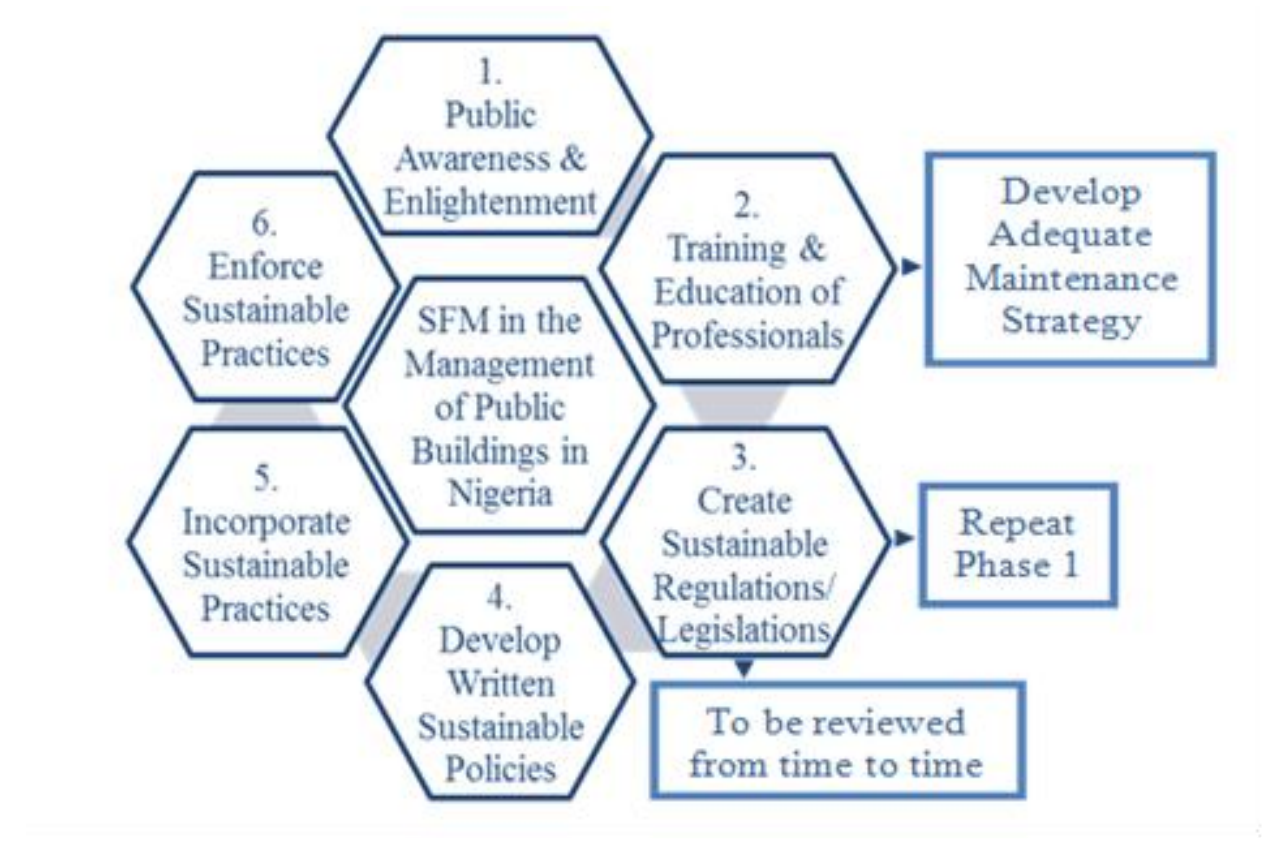

Figure 2. Framework for Embedding SFM in the Management of Public Buildings in Nigeria.

Phase 1 - Public awareness and enlightenment: The general public needs to be sensitised and enlightened of sustainable practices. Education of people is a strong tool for achieving sustainability. Since public buildings can be accessed by the general public, simple information fed to the public can assist in attaining sustainability. For example, simple practices like turning off the tap after using the washroom or immediately reporting leakages at the washroom to appropriate personnel will aid the sustainability course. Seminars and workshops can be organised in order to educate the public staff. However, based on the poverty level in Nigeria, the Government should not expect the public to embrace the course towards achieving sustainability without some form of criticism, rather the Government should be very strategic with their awareness programmes.

Phase 2 - Training and education of professionals: The training and education of the professionals involved in the management of public buildings is an important factor to achieving sustainability. This phase should begin before the public awareness and enlightenment phase come to an end. The training and education of professionals should be a continuous process in order to ensure that the professionals have vast knowledge in the practice of SFM/property management. Also, at this phase an appropriate maintenance strategy should be developed for the maintenance of public buildings.

Phase 3 - Create sustainable regulations/legislations: Just like most European countries, it is necessary to create sustainable regulations/legislations in order to protect and restore the environment. Regulations/legislations are important tools to achieve sustainability. The regulations/legislations should be reviewed from time to time depending on the 
environmental concerns. Also, it is still important that at this phase another round of public awareness and enlightenment is undertaken.

Phase 4 - Public organisations should develop written sustainable policy: Based on the requirements of the regulations/legislations, public organisations should come up with written sustainable policies. Written policies guide the organisation in that inadequacies are easily observed. Working without a written sustainable policy might lead to misunderstanding within the organisation, as employees might be working with a perceived understanding of the organisation's sustainable policies.

Phase 5 - Incorporate sustainable practices in the management of public buildings: At this phase, it is assumed that the maintenance staff, public sector staff and the general public have a better understanding of the importance of sustainability in the management and operation of buildings. Thus, at this phase, sustainable practices can be employed.

Phase 6 - Enforce sustainable regulations/legislations: In order to ensure compliance, it is important to strategise ways of implementing the sustainable regulations and legislations. At this phase, the Government can come up with incentives, targets for carbon reduction and penalties.

\section{Conclusion}

This paper has produced insights on the practice of SFM in the management of public buildings in Nigeria and the UK. From the results, it can be ascertained that the introduction of regulations/legislations and targets by the UK Government has aided in minimising the severe effect of other barriers in the implementation of SFM in the management of public buildings. It can be established that the introduction of regulations/legislations which aids sustainable practices is beneficial to both the organisations and the world in that, it reduces the running/operational cost of the organisation and carbon emissions of buildings. It is therefore important that the action of the UK Government be embedded in Nigeria. Based on this, the paper recommended a framework for the implementation of SFM in the management of public buildings in Nigeria. However, based on the outcome of this research, it is necessary that a further research be carried out regarding the actual regulative/legislative framework that will enhance the implementation of SFM in the management of public buildings in Nigeria.

\section{References}

Adenuga, O. A., Olufowobi, M. B. and Raheem, A. A. (2010). Effective Maintenance Policy as a Tool for Sustaining Housing Stock in Downturn Economy. Journal of Building Performance, 1(1), 93-109.

Adewunmi, Y. and Ogunba, O. (2008). Facilities Management and the Estate Surveyor and Valuer: An Investigation of Attitudes of Nigerian Estate Surveyors. Journal of property Management, 10, 26-32.

Akerele, D. and Gidado, K. (2003). The Risks and Constraints in the Implementation of PFI/PPP in Nigeria. In: Greenwood, D J, ed. Proceedings of the 19th Annual ARCOM Conference, 3 - 5 September 2003, Brighton, United Kingdom. Association of Researchers in Construction Management, 379-391.

Alabi, M. O., Onimisi, U. U. and Christain, E. (2010). Privatisation of Public Enterprises and Nigeria Sustainable Development. Journal of Social Science, 2, 204-208. 
Anele, D. (2010). Public Property, Maintenance Culture and the Nigerian. Nigeria: The Punch.

CIBSE (2011). Campaign Grows for Roll out of DECs in Energy Bill. London: Chartered Institution of Building Services Engineers.

CIOB (2004). Sustainability and Construction. London: The Chartered Institute of Building.

Elmualim, A., Czwakiel, A., Valle, R., Ludlow, G. and Shah, S. (2009). The Practice of Sustainable Facilities Management: Design Sentiments and the Knowledge Chasm. Architectural Engineering and Design Management, 5, 91-102.

Elmualim, A., Shockley, D., Valle, R., Ludlow, G. and Shah, S. (2010). Barriers and Commitment of Facilities Management Profession to the Sustainability Agenda. Journal of Building and Environment, 45, 58-64.

Grant, Z., Garrod, A., Myers, K. and Nolan, M. (2009). Towards a Low Carbon Built Environment: A Road Map for Action. London: Royal Institute of Chartered Surveyors Report.

Index Mundi (2011). Nigeria Demographics profile 2011 [online]. Available from: http:// www.indexmundi.com/nigeria/demographics_profile.html [Accessed 31 July 2011].

Iyagba, R. O. A. (2005). The Menace of Sick Buildings: A Challenge to all for its Prevention and Treatment. Nigeria: University of Lagos Press.

Kadir, M. R. A., Lee, W. P., Jaafar, M. S., Sapuan, S. M. and Ali, A. A. A. (2005). Factors Affecting Construction Labour productivity for Malaysian Residential Projects. Journal of Structural Survey, 23(1), 42-54.

Lewis, A., Elmualin, A. and Riley, D. (2011). Linking Energy and Maintenance Management through Three American Case Studies. Journal of Facilities, 29, $243-$ 254.

Nielsen, S. B., Jensen, J. O. and Jensen, P. A. (2009). Delivering Sustainable Facilities Management in Danish Housing Estates. Proceedings of the CIMNE 2009 international conference on Sustainability Measurement and Modelling, Barcelona, Spain.

Nwanze, S. (2010). Nigeria: Is Bureau of Public Enterprise at a Cross Road? Nigeria: Daily Champion.

Nwoye, M. I. (2002). A Focus Group Discussion Approach to the Comparative Analysis of private and Public Sector Enterprises in Nigeria. Technovation, 22,525-534.

Olakunle, F. T. (2010). Evaluation of the Performance of Hard Services in Public Enterprises. Case Study: Nigeria. Thesis (MSc), University of Brighton, United Kingdom.

Olowu, D. and Sako, S. (2002). Better Goverance and Public Policy - Capacity Building for Democratic Renewal in Africa. USA: Kumarian Press Inc.

Shah, S. (2007). Sustainable Practice for the Facilities Management. Oxford: Blackwell Publishing.

Ravetz, J. (2008). State of the Stock - What Do We Know About Existing Buildings and Their Future Prospects? Energy Policy, 36, 4462-4470.

Stern Review. The Economics of Climate Change [online]. Available from: http:// mudancasclimaticas.cptec.inpe.br/ rmclima/pdfs/destaques/sternreview_report_co mplete. pdf [Accessed 14 June 2011].

Transparency International (2010). Corruption Perceptions Index 2010 Results [online]. http://www.transparency.org/policy_research/surveys_indices/cpi/2010/results. [Accessed 3 June 2011].

UNEP (2007). Buildings and Climate Change - Status, Challenges and Opportunities. 
United Nations Environment Programme.

Williams, D. and Sutrisna, M. (2010). An Evaluation of the Role of facilities Managers in Managing sustainability and the Remedial Actions in Reducing $\mathrm{CO}_{2}$ Emissions in the Built Environment. Proceedings of COBRA 2010, 2 - 3 September 2010, Paris, France.

World Bank (2011). Climate Change and the World Bank [on-line]. Available from: http:// climatechange.worldbank.org/overview [Accessed 10 April 2011].

World Commission on Environment and Development. Our Common Future. Available from: http://upload.wikimedia.org/wikisource/en/d/d7/our-common-future.pdf [Accessed 15 June 2011]. 